\title{
Portal Annular Pancreas - A Case Report
}

\author{
Padmavathi G', Varalakshmi KL ${ }^{2}$, Jyothi N Nayak ${ }^{3}$ \\ ${ }^{1}$ Dr Padmavathi G, Associate Professor, ${ }^{2}$ Dr Varalakshmi KL, Assistant Professor, ${ }^{3}$ Mrs.Jyothi N Nayak, Tutor. \\ All are affiliated to Department of Anatomy, MVJ Medical College \& Research Hospital, Bangalore, Karnataka, INDIA.
}

Address for correspondence: Dr. Padmavathi.G, Email: paddu78@gmail.com

\begin{abstract}
Portal annular pancreas is one of the rarest congenital anomaly of the pancreas. This variation was noted in a formalin fixed male cadaver aged about 60 yrs during the course of routine anatomy dissection in MVJ Medical college and research hospital.Here the pancreatic parenchyma not only enclosed the second part of duodenum but also had surrounded the portal vein $(\mathrm{PV})$. Such a variation requires careful consideration by the surgeon and gastroenterologists while performing pancreatic resection and various other procedures pertaining to the pancreas and duodenum.
\end{abstract}

Key words: Congenital anomaly, Portal vein, Pancreatic resection

\section{Introduction}

Portal annular pancreas (PAP) is also known as circumportal pancreasis an uncommon and rare congenital anomaly of the pancreas. It mostly remains asymptomatic but can have serious implications if a pancreatic surgery is being contemplated. In contrast to a conventional annular pancreas in which the pancreatic tissue encircles the second part of the duodenum, portal annular pancreas is characterized by encasement of the portal vein or the superior mesenteric vein (SMV) by a rind of pancreatic parenchyma [1].

The first case of portal annular pancreas was documented in 2007 by Hamanaka [2] and second case by Marjanovic in 2007 [3]. Leyendecker and Baginski [4] in 2008 studied imaging features of 4 cases of this anatomical variant and coined the term circumportal pancreas. In 1987 Sugiura reported a case of pancreatic tissue wrapping around the superior mesenteric artery[1].

The incidence of annular pancreas is 3 in 20,000 autopsies [5] and incidence of portal annular pancreas is $1.14 \%-2.5 \%$ as reported by Karasaki et al. and Ishigami $[6,7]$. Recent progress has made it possible to diagnose PAP preoperatively with contrast-enhanced multidetector computed tomography (MDCT) or magnetic resonance imaging [2].

\section{Case report}

During the routine dissection for the undergraduates students in the department of anatomy of MVJ Medical
College and Research Hospital, we encountered this rarest variation in a male cadaver aged $60 \mathrm{yrs}$. The dissection was carried out as per the Cunningham's manual of practical anatomy to expose the retroperitoneal part of the duodenum and pancreas. We noted that the pancreatic tissue encircled the second part of the duodenum and a rind of pancreatic parenchyma extends further to encircle the portal vein. [Fig:1 \& Fig:2].

The main pancreatic duct was situated anterior to the portal vein and it opened into the second part of the duodenum. We also noticed an accessory right hepatic artery arising from the cystic artery during the dissection. The variations were photographed using digital camera. (Sony cybershot-14 Mega pixel)

\section{Discussion}

Pancreas divisum, annular pancreas, and portal annular pancreas are some of the pancreatic fusion anomalies [8]. Embryologically pancreas is developed from the ventral and a dorsal bud of the primitive foregut.

The ventral bud forms the major part of the head and the uncinate process, whereas the dorsal bud forms upper part of the head, the body, and tail of the pancreas. The ventral bud rotates posteriorly during the $7^{\text {th }}$ week of gestation to fuse with the dorsal bud to form a fully mature gland. Rarely, this fusion occurs to the left of the superior mesenteric or portal vein, resulting in a rind of 


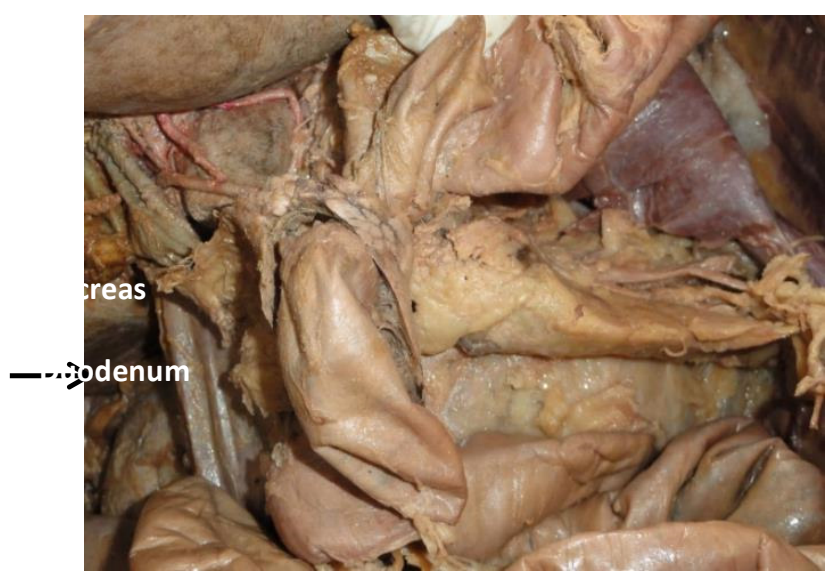

Fig 1: Figure showing the pancreas encircling the second part of the duodenum and the portal vein

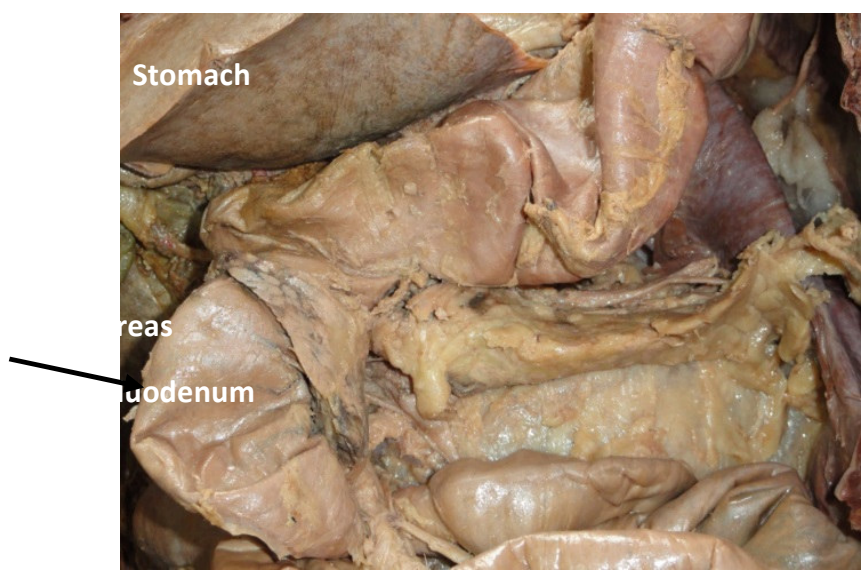

Fig 2:Figure showing the second part of duodenum encircled by pancreatic tissue (annular pancreas).

AP- Annular pancreas, PAP- Portal annular pancreas, PV- Portal vein pancreatic parenchyma encircling the portal vein or SMV. This has been referred to as the portal annular pancreas and is a common finding in pigs [9, 10]. Recent studies in animal models revealed that there are molecular and behaviour differences between the dorsal and ventral pancreas [11].

The annular pancreas surrounds the duodenum completely or incompletely. The symptoms vary with the degree of duodenal obstruction. A bypass operation such as duodeno-jejunostomy is needed if there are obstructive symptoms, whereas the PAP is asymptomatic and usually noted during operations. So far about 10 cases of PAP have been reported in the literature,but some authors conclude that the prevalence of portal annular pancreas is not extremely low but the condition is not readily recognized on preoperative imaging due to lack of adequate knowledge and awareness of this uncommon variant [12].

Joseph [13] has classified PAP into 3 types. In type I the ventral bud of the pancreas fuses with the dorsal bud posterior to the portal vein with a retroportal pancreatic duct; type II has concomitant pancreas divisum; and type III is when the uncinate process alone is involved and the pancreatic duct is seen anterior to the portal vein (anteportal pancreatic duct).In our case we encountered type III PAP. Portal annular pancreas is also classified into suprasplenic, infra-splenic and mixed types according to the level of pancreas fusion by Karasakiet al [6]. Recent retrospective studies of image records revealed an unexpectedly high incidence of this variant.

Imaging plays a pivotal role in the diagnosis of portal annular pancreas and contrast-enhanced multi-detector 
computed tomography (MDCT) is considered sufficient enough to establish the diagnosis. MRI is especially useful for depicting the major as well as the accessory duct systems and thus can aid in differentiating anteportal and retroportal pancreatic duct [14].

The clinical importance lies in accurately identifying portal annular pancreas on preoperative imaging, especially in patients where a pancreatic surgery is being contemplated so as to avert inadvertent pancreatic injury and the attendant risk of postsurgical pancreatic fistula. It is thus imperative to be aware of and carefully search for uncommon pancreatic anomalies, such as portal annular pancreas, in patients planned for pancreatic resection, so as to avoid and minimize any surgical complications [15]. Surgeons performing procedures like pancreas transplantation, islet cell isolation and transplantation, should bear in mind this rare pancreatic condition prior to surgical intervention to avoid complications, and to provide patients with welldesigned, case-specific pancreatic surgery.

\section{References}

1. Sugiura Y, Shima S, Yonekawa H, Yoshizumi Y, Ohtsuka H, Ogata T. The hypertrophic uncinate process of the pancreas wrapping the superior mesenteric vein and artery—a case report.Jpn J Surg 1987; 17:182-5.

2. Hamanaka Y, Evans J, Sagar G, Neoptolemos JP. Complete pancreatic encasement of the proximal hepatic portal vein: a previously undescribed congenital anomaly. Br J Surg 1997;84:785.

3. Marjanovic G, Obermaier R, Benz S, Bley T, Juettner E, Hopt UT, et al. Complete pancreatic encasement of the portal vein- surgical implication of an extremely rare anomaly. Langenbecks Arch Surg 2007;392:489-91.

4. Leyendecker JR, Baginski SG, Complete pancreatic encasement of the portal vein (circumportal pancreas): imaging findings and implications of a rare pancreatic anomaly. J Comput Assist Tomogr 2008;32:61-4.

5. Tatsuya Kin and James Shapiro AM, Surgical aspects of human islet isolation. Islets 2010;2(5): 265-273.
6. Karasaki H, Mizukami Y, Ishizaki A, Goto J, Yoshikawa D, Kino S, et al. Portal annular pancreas, a pancreatic malformation: Frequency, morphology, and implications for pancreatic surgery. Surgery.2009;146:515-8.

7. Ishigami K, Tajima $T$, Nishie A, Asayama $Y$, Kakihara D, Nakayama $T$, et al. The prevalence of circumportal pancreas as shown by multidetector-row computed tomography. Insights Imaging.2011;2:409-14

8. Kin T, Shapiro AMJ, Lakey JRT. Pancreas divisum: study in the cadaveric donor pancreas for islet isolation. Pancreas.2005;30:325-7.

9. Kin T, Shapiro AMJ, Ryan EA, Lakey JRT. Islet isolation and transplantation from an annular pancreas: a case report. J Pancreas.2005;6:274-6.

10. Ferrer J, Scott WE, 3rd, Weegman BP, Suszynski TM, Sutherland DER, Hering BJ, et al. Pig pancreas anatomy: implications for pancreas procurement, preservation and islet isolation. Transplantation.2008; 86:1503-10.

11. Gittes GK. Developmental biology of the pancreas: A comprehensive review. Dev Biol. 2009;326:4-35.

12. Hwang SS, Paik CN, Lee KM, et al. Recurrent acute pancreatitis caused by an annular pancreas in a child. GastrointestEndosc.2010;72:848-849.

13. Joseph P, Raju RS, Vyas FL, Eapen A, Sitaram V. Portal annular pancreas. A rare variant and a new classification.JOP. 2010;11:453-5.

14. Gonoi W, Akahane M, Akai H, Hagiwara K, Kiryu $\mathrm{S}$, Hayashi N, et al. Retroportal main pancreatic duct with circumportal pancreas: Radiographic visualization. Clin Imaging. 2011;35:442-6.

15. Matsumoto I, Shinzeki M, Fukumoto T, Ku Y. An extremely rare portal annular pancreas for pancreaticoduodenectomy with a special note on the pancreatic duct management in the dorsal pancreas.Surgery. 2013 Mar;153(3):434-6.

\section{How to cite this article?}

Padmavathi G, Varalakshmi KL, Jyothi N Nayak. Portal Annular Pancreas - A Case Report. Int J Med Res Rev 2014;2(3):259- 261. doi:10.17511/ijmrr. 2014.i03.16. 